\title{
Multiaxial Cycle Deformation and Low-Cycle Fatigue Behavior of Mild Carbon Steel and Related Welded-Metal Specimen
}

\author{
Weilian Qu, Ernian Zhao, and Qiang Zhou \\ Hubei Key Laboratory of Roadway Bridge \& Structure Engineering, Wuhan University of Technology, Wuhan, Hubei 430070, China \\ Correspondence should be addressed to Ernian Zhao; zhaoern@126.com
}

Received 4 July 2016; Revised 10 December 2016; Accepted 19 January 2017; Published 13 February 2017

Academic Editor: Luciano Lamberti

Copyright (C) 2017 Weilian Qu et al. This is an open access article distributed under the Creative Commons Attribution License, which permits unrestricted use, distribution, and reproduction in any medium, provided the original work is properly cited.

\begin{abstract}
The low-cycle fatigue experiments of mild carbon Q235B steel and its related welded-metal specimens are performed under uniaxial, in-phase, and $90^{\circ}$ out-of-phase loading conditions. Significant additional cyclic hardening for $90^{\circ}$ out-of-phase loading conditions is observed for both base metal and its related weldment. Besides, welding process produces extra additional hardening under the same loading conditions compared with the base metal. Multiaxial low-cycle fatigue strength under $90^{\circ}$ out-of-phase loading conditions is significantly reduced for both base-metal and welded-metal specimens. The weldment has lower fatigue life than the base metal under the given loading conditions, and the fatigue life reduction of weldment increases with the increasing strain amplitude. The KBM, FS, and MKBM critical plane parameters are evaluated for the fatigue data obtained. The FS and MKBM parameters are found to show better correlation with fatigue lives for both base-metal and welded-metal specimens.
\end{abstract}

\section{Introduction}

Engineering components are always subjected to complex cycle loading during the service period, and the failure eventually occurs due to the accumulated fatigue damage [1]. In engineering applications, fatigue failures occur in local regions, where stress concentrations generate multiaxial stress/strain states [2]. The multiaxial stress/strain states commonly arise from multidirectional external loads, notch effects, and complex geometric features, which indeed influence the fatigue strength of engineering components [3].

Understanding of multiaxial fatigue strength of metallic materials is always based upon the experimental observations from thin-walled tubular specimens under axial-torsional loading. For a long period, the multiaxial fatigue tests are mainly focused on the base material of metals. A review of the multiaxial fatigue experiments for metallic materials can be found in [4,5]. In the last decade, Chen et al. [6] studied the multiaxial strength of type 304 stainless steel under sequential biaxial loading. Gao et al. [7, 8] tested the multiaxial fatigue strength of $16 \mathrm{MnR}$ steel and 7075-T651 aluminum alloy under various multiaxial loading paths. Shang and Wang [9] conducted the fatigue tests on hot-rolled medium-carbon 45 steel under the axial-torsional loading using sinusoidal wave forms. The multiaxial cycle deformation and fatigue behaviors of type 304 stainless steel and medium-carbon 1050 steel are studied by Shamsaei [10]. Gladskyi and Shukaev [11] conducted the contrastive analysis of the uniaxial and multiaxial low-cycle fatigue strength of type BT1-0 titanium alloy.

For welded steel structures, residual stresses, welding defects, material inhomogeneity in the weld zone, and so forth caused by the welding process can significantly reduce the fatigue strength of the welded joints [12-14]. At present, the fatigue design of welded joints is mainly based on the fatigue resistance $S-N$ curves, which are obtained from the statistical analysis of the uniaxial fatigue test results of classified welding structural details [15-17]. However, multiaxial fatigue of welded joints is rarely investigated. Chen et al. [18] conducted the low-cycle fatigue experiments on $1 \mathrm{Cr}-18 \mathrm{Ni}-9 \mathrm{Ti}$ stainless steel and related weld metal under axial, torsional, and $90^{\circ}$ out-of-phase loading. Fatigue of welded components under bending-torsion proportion and nonproportion loading was studied in [19].

The multiaxial fatigue of metallic materials has attracted a widespread attention in the past decades. Investigations on multiaxial fatigue are often conducted by using an equivalent parameter which makes it possible to compare the multiaxial 


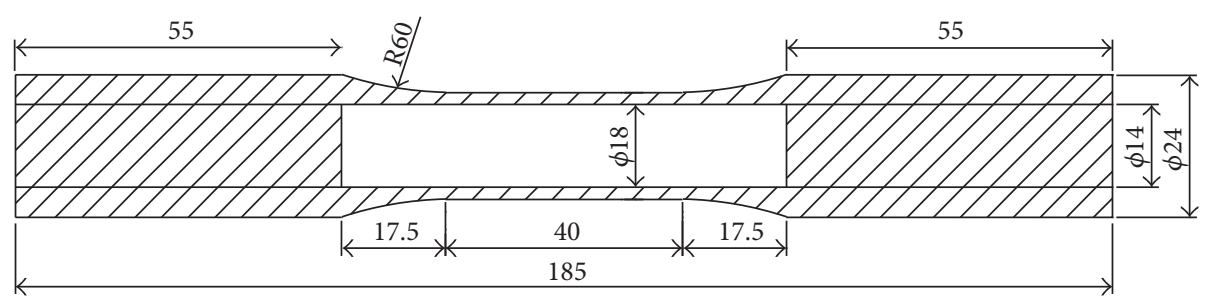

FIgURE 1: Geometry of the base-metal specimen.

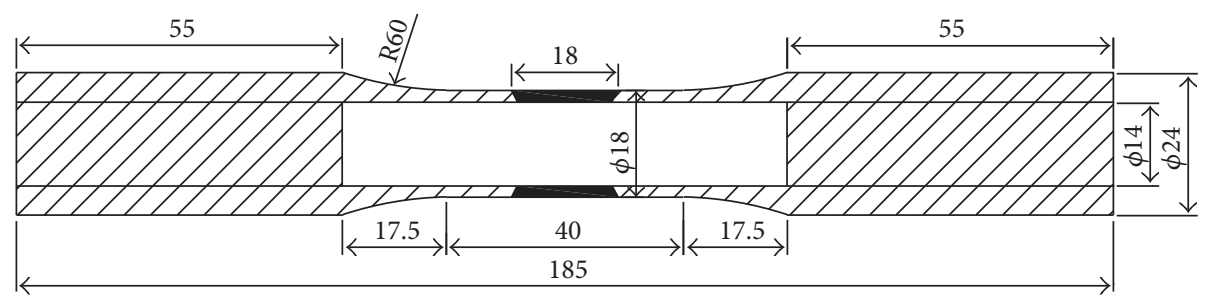

FIGURE 2: Geometry of the welded-metal specimen.

TABLE 1: Chemical composition of Q235B steel (wt\%).

\begin{tabular}{lccccccc}
\hline $\mathrm{C}$ & $\mathrm{Mn}$ & $\mathrm{Si}$ & $\mathrm{P}$ & $\mathrm{S}$ & $\mathrm{V}$ & Alt & $\mathrm{Nb}$ \\
\hline 0.16 & 0.45 & 0.26 & 0.021 & 0.025 & 0.006 & 0.004 & 0.003 \\
\hline
\end{tabular}

loading with uniaxial one [20]. Then the fatigue analysis methods developed for the uniaxial case can be employed to solve the multiaxial fatigue problems. The well-known Manson-Coffin criterion, which is widely used in the uniaxial low-cycle fatigue analysis, is modified for the multiaxial loading condition. In the recent decades, the Manson-Coffin criterion in terms of critical plane parameters, such as KBM and FS parameters, plays an important role in the multiaxial fatigue damage evaluation (more details are given in [21, 22]).

To study the multiaxial cycle deformation and low-cycle fatigue behaviors of mild carbon Q235B welded joints, which are more and more widely used in the steel constructions in China, the fatigue experiments are conducted on Q235B steel and its weldment by using thin-walled tubular specimens under fully reversed strain-controlled loading conditions with uniaxial, in-phase, and $90^{\circ}$ out-of-phase loading. The KBM, FS, and MKBM critical plane parameters are evaluated for the experimental data gathered in this study.

\section{Experimental Procedure}

2.1. Materials and Specimens. The investigated material in the present study is mild carbon Q235B structural steel, which is widely used in China's steel constructions. The investigated Q235B steel has Young's modulus of $204 \mathrm{GPa}$, yield strength of $270 \mathrm{MPa}$, ultimate strength of $390 \mathrm{MPa}$, Poisson's ratio of 0.3 , and elongation of $36.9 \%$. The chemical composition of Q235B steel is presented in Table 1.

The base-metal specimen has a tubular geometry with the outside and inside diameters of $18 \mathrm{~mm}$ and $14 \mathrm{~mm}$, respectively. The wall thickness in the gage section is $2 \mathrm{~mm}$.
TABLE 2: Chemical composition of welding wire (wt\%).

\begin{tabular}{lccccccccc}
\hline $\mathrm{C}$ & $\mathrm{Mn}$ & $\mathrm{Si}$ & $\mathrm{P}$ & $\mathrm{S}$ & $\mathrm{V}$ & $\mathrm{Ni}$ & $\mathrm{Cr}$ & $\mathrm{Mo}$ & $\mathrm{Cu}$ \\
\hline 0.077 & 1.54 & 0.92 & 0.011 & 0.012 & 0.002 & 0.006 & 0.023 & 0.004 & 0.126 \\
\hline
\end{tabular}

The geometry of the base-metal specimen is displayed in Figure 1.

The welded specimen is made by the manual $\mathrm{CO}_{2}$ gasshielded welding process. The welding wire of MG70S- 6 with a diameter of $2 \mathrm{~mm}$ is used. The chemical composition of welding wire is presented in Table 2.

The manufacture of the welded metal specimen is followed by [18]. A well-designed notch is first machined at the center of the base metal bar, and the notch is then filled with weld metal. Finally, the welded-metal specimen is machined to the shape in accordance with the base-metal specimen. The manufactured welded-metal specimen has an $18 \mathrm{~mm}$ long welded zone at the center of the gauge length. The geometry of the welded thin-walled tubular specimen tested is identical to the base one (see Figure 2).

The monotonic mechanical properties for the base-metal and welded-metal specimens are listed in Table 3.

2.2. Fatigue Tests. Fatigue tests under uniaxial, in-phase, and $90^{\circ}$ out-of-phase loading conditions are conducted under the fully reversed strain-controlled loading at constant amplitudes. The applied waveforms for both base-metal and welded-metal specimens are sinusoidal. The three test strain paths are displayed in Figure 3. The horizontal axis is the term of axial strain, $\varepsilon$, and the vertical axis is the term of shear strain, $\gamma / \sqrt{3}$. The correlation of the horizontal axis and the vertical axis is derived from the von Mises criterion of $\bar{\varepsilon}=\sqrt{\varepsilon^{2}+(1 / 3) \gamma^{2}}$ in which $\bar{\varepsilon}$ is the equivalent von Mises strain. 
TABLE 3: Mechanical properties of Q235B base and welded metal.

\begin{tabular}{lcccccc}
\hline & $\begin{array}{c}\text { Young's } \\
\text { modulus } \\
E(\mathrm{GPa})\end{array}$ & $\begin{array}{c}\text { Shear } \\
\text { modulus } \\
G(\mathrm{GPa})\end{array}$ & $\begin{array}{c}\text { Yield } \\
\text { strength } \\
\sigma_{y}(\mathrm{MPa})\end{array}$ & $\begin{array}{c}\text { Tensile } \\
\text { strength } \\
\sigma_{u}(\mathrm{MPa})\end{array}$ & $\begin{array}{c}\text { Ultimate } \\
\text { strain }\end{array}$ & $\begin{array}{c}\text { Elongation } \\
\varepsilon_{u}(\%)\end{array}$ \\
\hline Base metal & 204 & 81.4 & 269 & 390.9 & 15.2 & 36.9 \\
Welded metal & 198 & 76.3 & 265 & 371.3 & 4.39 & 14.3 \\
\hline
\end{tabular}

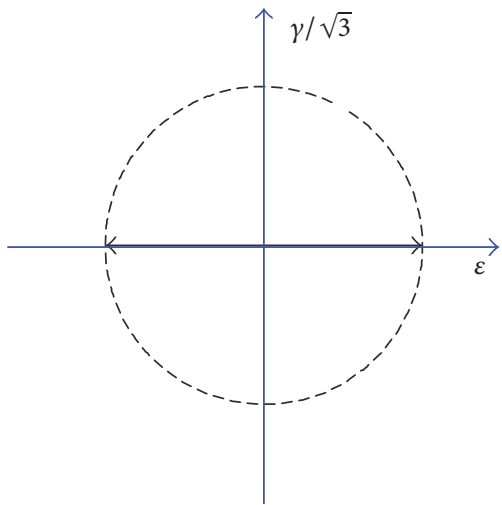

(a)

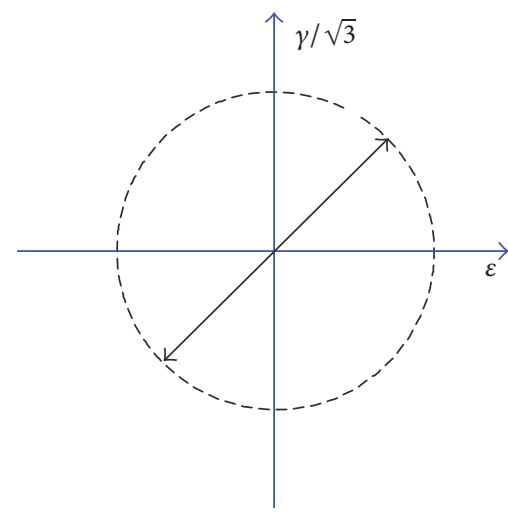

(b)

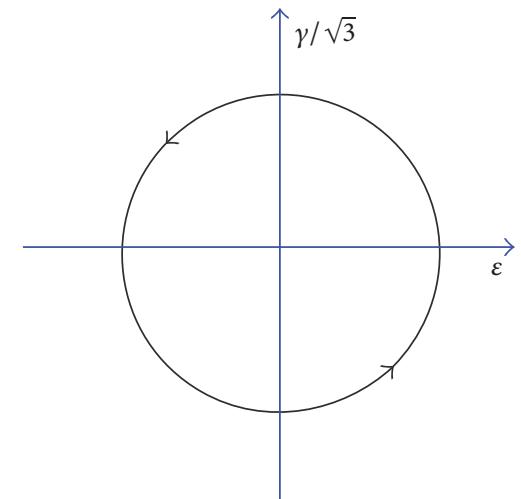

(c)

FIGURE 3: Fatigue test loading paths: (a) uniaxial (UA), (b) in-phase (IP), and (c) $90^{\circ}$ out-of-phase (OP).

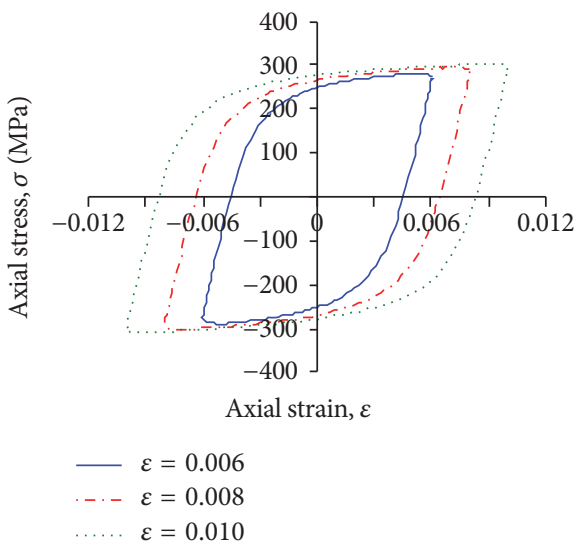

(a)

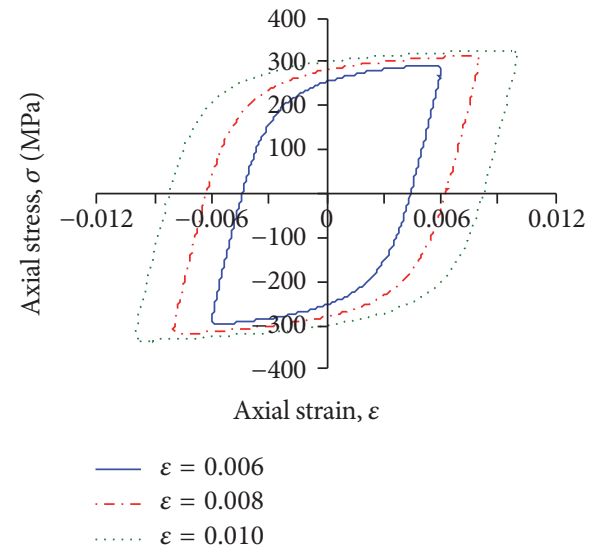

(b)

FIGURE 4: Axial hysteresis loops for uniaxial loading: (a) base metal and (b) welded metal.

Fatigue tests were conducted on an MTS tension-torsion machine under strain-controlled loading using a tensiontorsion strain extensometer with the gauge length of $25 \mathrm{~mm}$, which is mounted at the center of the outside of the specimen gauge section to measure the strain responses. The loading frequency for constant-amplitude tests is $1.0 \mathrm{HZ}$. Fatigue life is assumed as the number of cycles for which there is $30 \%$ reduction with respect to the maximum tensile or shear stress of the uniaxial test.

\section{Results and Discussion}

The stable hysteresis loops of base-metal and welded-metal specimens under uniaxial, in-phase, and $90^{\circ}$ out-of-phase loading at different strain amplitude are presented in Figures 4-6, respectively. It can be observed that the multiaxial cycle deformation behavior for in-phase loading condition is basically the same as the uniaxial one, while the multiaxial cycle deformation behaviors for out-of-phase loading condition significantly changed. The maximum shear and axial stress responses as well as shear and axial strains are simultaneous under in-phase loading conditions for both base-metal and welded-metal specimen. However, the maximum values of cyclic stress and strain responses do not always occur at the same time under the $90^{\circ}$ out-of-phase loading, which indicates that the metal's plastic yield flow for $90^{\circ}$ out-ofphase loading condition is different from that under the uniaxial one. 

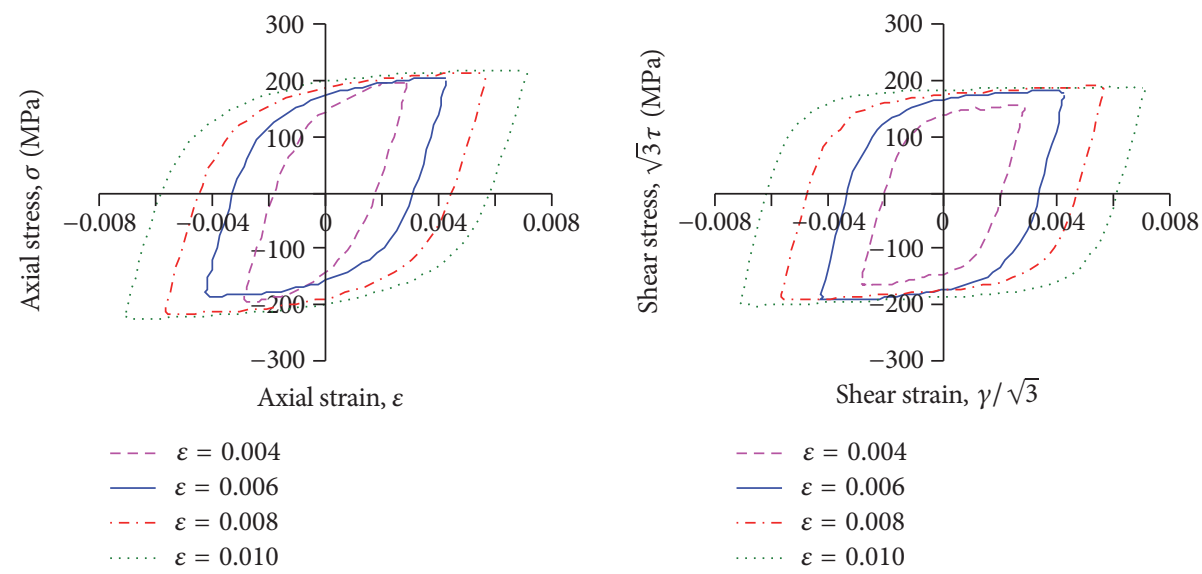

(a)
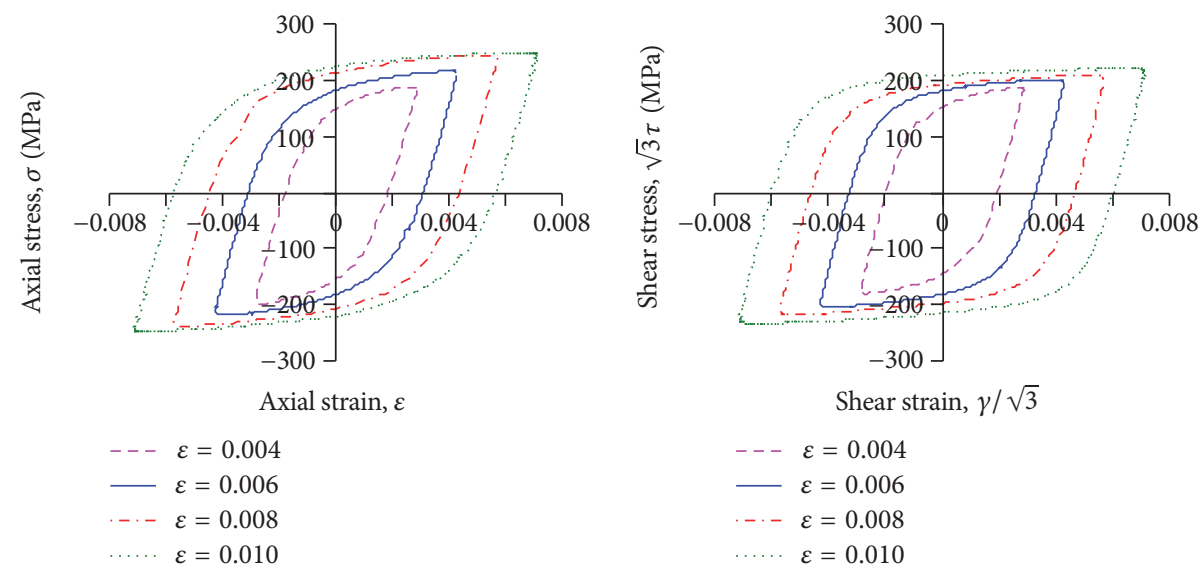

(b)

Figure 5: Axial (left) and shear (right) hysteresis loops for in-phase loading: (a) base metal and (b) welded metal.

Crack initiation under uniaxial fatigue test is in the circumferential direction as usual. In the in-phase fatigue test, the patterns of the macroscopic crack are observed similar to that of uniaxial fatigue test. For the $90^{\circ}$ out-ofphase fatigue test, the crack direction is irregular because the maximum principal stress direction changed with respect to the nonproportionality loading condition, and the fracture shape of the macrocrack for $90^{\circ}$ out-of-phase fatigue test was jagged. The crack patterns for base metal and welded metal under in-phase and out-of-phase loading conditions are shown in Figures 7 and 8, respectively.

The fatigue experimental and analytical results for the base-metal and welded-metal specimens under uniaxial, in-phase, and $90^{\circ}$ out-of-phase loading are presented in Table 4 . The table includes axial and shear stress and strain amplitudes, maximum shear strain amplitude acting on the maximum shear plane (critical plane), $\Delta \gamma_{\max } / 2$, strain ration, the normal strain range acting on the critical plane, $\Delta \varepsilon_{n}$, maximum normal stress acting on the critical plane, $\sigma_{n, \max }$, and strain ration parameter, $\lambda$, for each fatigue test.
The stabilized cycle stress-strain relationship can be represented by the Ramberg-Osgood equation [23, 24].

$$
\frac{\Delta \bar{\varepsilon}}{2}=\frac{\Delta \bar{\varepsilon}_{e}}{2}+\frac{\Delta \bar{\varepsilon}_{p}}{2}=\frac{\Delta \bar{\sigma}}{2 E}+\left(\frac{\Delta \bar{\sigma}}{2 K^{\prime}}\right)^{1 / n^{\prime}}
$$

where $K^{\prime}$ is the cyclic hardening coefficient and $n^{\prime}$ is the cyclic hardening exponent, $E$ is Young's modulus of the investigated material, and $\Delta \bar{\varepsilon}$ and $\Delta \bar{\sigma}$ are the equivalent strain range and the equivalent stress range, respectively. $\Delta \bar{\varepsilon}_{e}$ and $\Delta \bar{\varepsilon}_{p}$ are the equivalent elastic strain range and the equivalent plastic strain range, respectively. The equivalent elastic strain can be calculated based on Hooke's law. The equivalent plastic strain range can be then calculated by

$$
\frac{\Delta \bar{\varepsilon}_{p}}{2}=\frac{\Delta \bar{\varepsilon}}{2}-\frac{\Delta \bar{\varepsilon}_{e}}{2}=\frac{\Delta \bar{\varepsilon}}{2}-\frac{\Delta \bar{\sigma}}{2 E} .
$$

Comparison of cyclic stress-strain curves between base metal and welded metal for uniaxial, in-phase, and out-ofphase loading conditions is presented in Figure 9, in which the solid lines and the dotted lines are the fitted cyclic stressstrain curves for base-metal specimens and welded-metal 

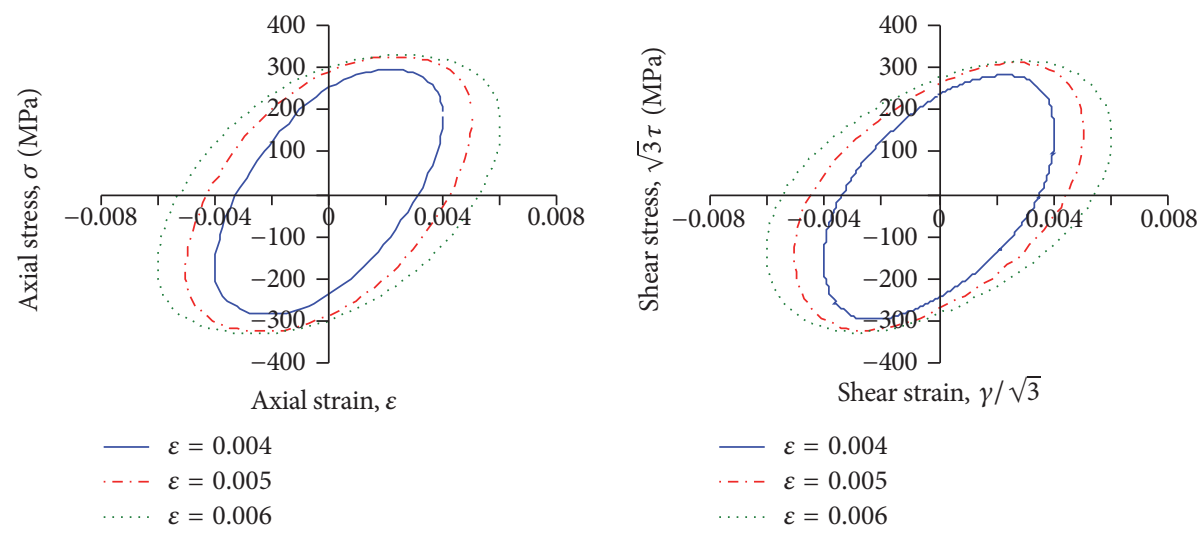

(a)
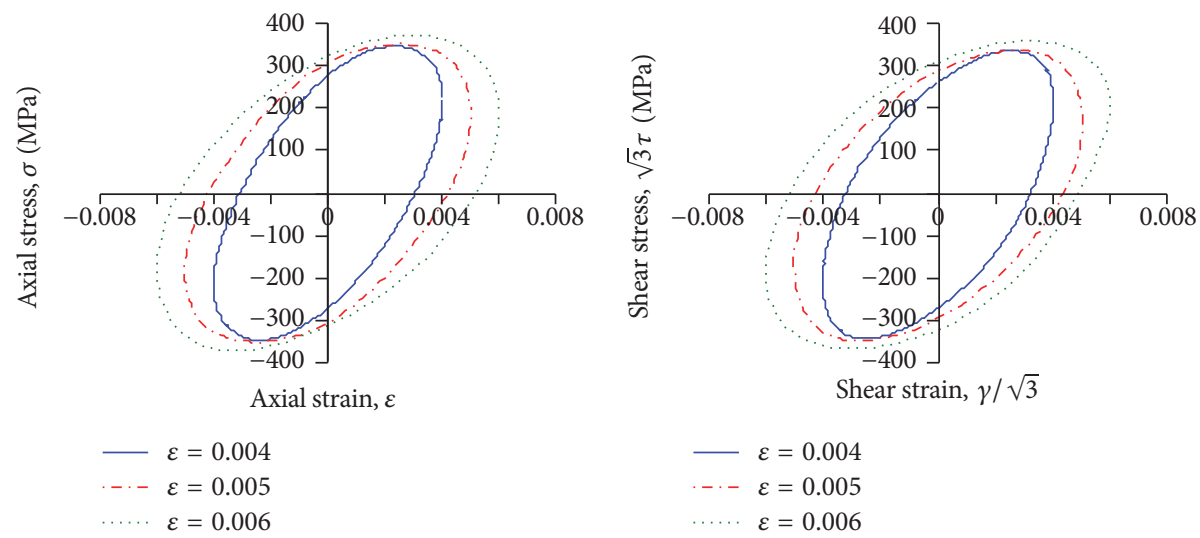

(b)

FIGURE 6: Axial (left) and shear (right) hysteresis loops for out-of-phase loading: (a) base metal and (b) welded metal.

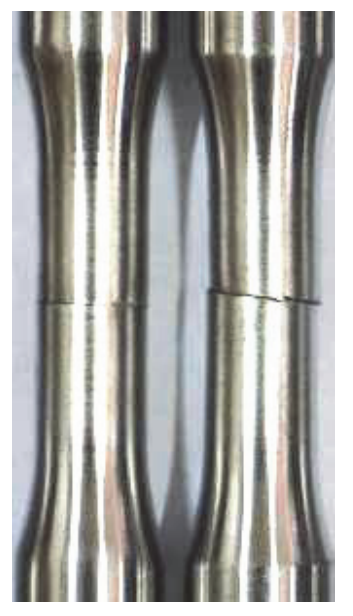

(a)

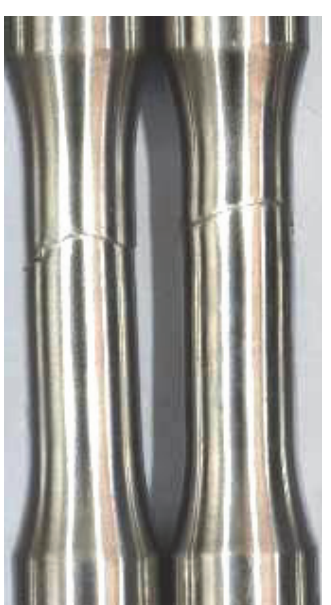

(b)

Figure 7: Patterns of crack growth for in-phase test: (a) base metal and (b) welded metal.

specimens, respectively. It can be seen that the fitted cyclic stress-strain curves for both base metal and welded metal under in-phase loading are similar to those obtained for uniaxial loading, while the fitted cyclic stress-strain curves for the $90^{\circ}$ out-of-phase loading conditions are above those relative to the uniaxial loading case, which indicates that a significant additional cyclic hardening effect occurs for both base metal and welded metal under the out-of-phase loading 


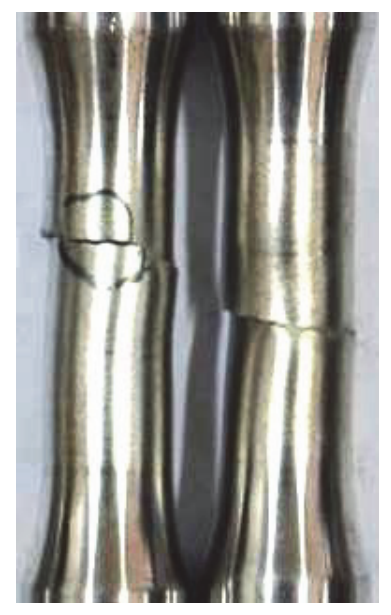

(a)

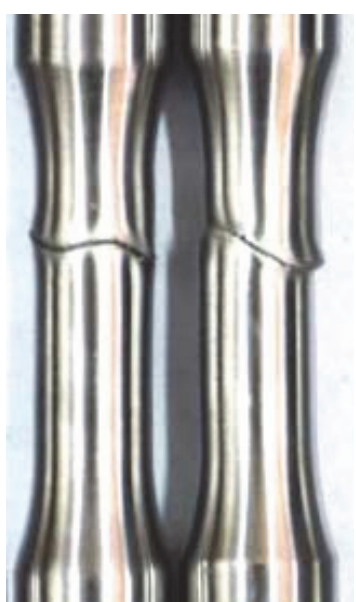

(b)

FIGURE 8: Patterns of crack growth for out-of-phase test: (a) base metal and (b) welded metal.

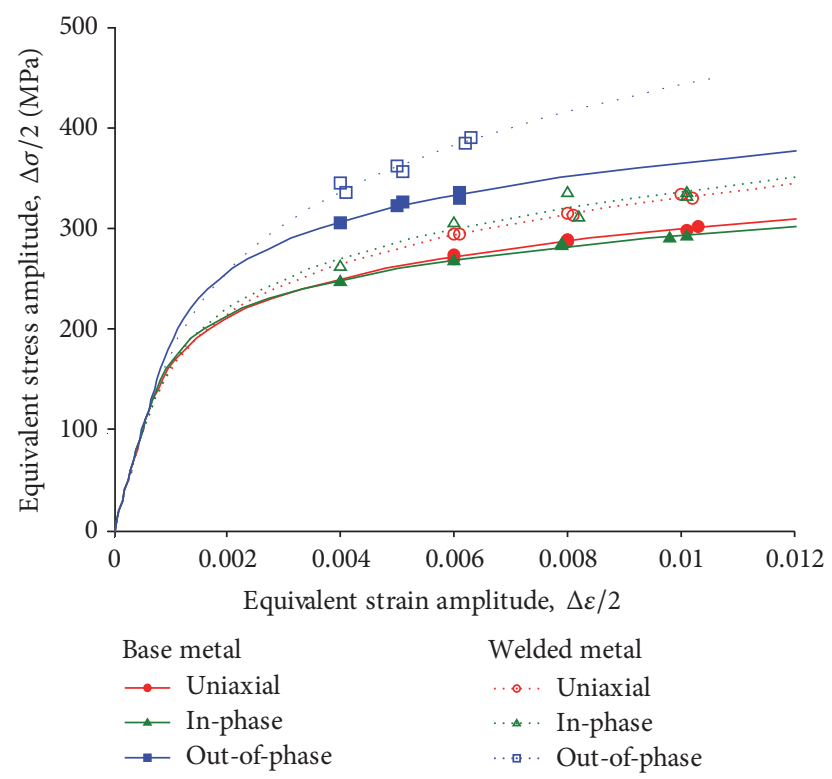

FIgURE 9: Comparison of cyclic stress-strain curves between base metal and welded metal for uniaxial, in-phase, and out-of-phase loading conditions.

conditions. It can be also seen that the stabilized cyclic stressstrain curves of the welded metal are over those of the base metal under the same loading condition. It can be concluded that the welding process produces extra additional hardening for the weldment compared with the base metal.

\section{Fatigue Life Analysis}

The Manson-Coffin equation in terms of the equivalent strain parameter for fatigue evaluation under uniaxial loading can be written as [20-22]

$$
\frac{\Delta \bar{\varepsilon}}{2}=\frac{\sigma_{f}^{\prime}}{E}\left(2 N_{f}\right)^{b}+\varepsilon_{f}^{\prime}\left(2 N_{f}\right)^{c},
$$

where $\Delta \bar{\varepsilon}$ is the equivalent von Mises strain range, $N_{f}$ is the cycle numbers to fatigue failure, and $\sigma_{f}^{\prime}, \varepsilon_{f}^{\prime}, b$, and $c$ are the fatigue strength coefficient, the fatigue ductility coefficient, the fatigue strength exponent, and the fatigue ductility exponent, respectively. The fatigue properties fitted by (3) for the base metal and welded metal under the uniaxial, in-phase, and $90^{\circ}$ out-of-phase loading are listed in Table 5.

The relationships of equivalent strain parameters versus fatigue life under the investigated loading conditions are shown in Figure 10(a) for the base-metal specimens and in Figure 10(b) for the welded-metal specimens, respectively. It can be seen that the fatigue life under in-phase loading conditions is slightly longer than that under uniaxial loading conditions for both base metal and welded metal, while the fatigue life for $90^{\circ}$ out-of-phase loading conditions is significantly reduced for both base metal and welded metal compared with the uniaxial case. Therefore, the following conclusion can be drawn: the equivalent strain parameter is not well correlated with fatigue life in the case of out-of-phase loading.

Fatigue lives of base-metal and welded-metal specimen for the three investigated loading conditions are compared in Figure 11. It can be observed that the fatigue life of weldedmetal specimen is greatly reduced compared with that of base metal under the same loading conditions, and the fatigue life reduction of weldment increases with increasing strain amplitude.

\section{Critical Plane Parameters}

Three strain-based critical plane parameters, which are adopted to correlate the fatigue life for the different loading conditions, are investigated in this section.

Kandil-Brown-Miller [22] takes the linear combination of the shear and the normal strain ranges acting on the critical plane as the fatigue parameter. The correlation of the KBM parameters and fatigue lives can be obtained by employing 
TABLE 4: Fatigue test and analysis results for base-metal and welded-metal specimens.

\begin{tabular}{|c|c|c|c|c|c|c|c|c|c|}
\hline Strain paths & $\begin{array}{c}\frac{\Delta \varepsilon}{2} \\
(\%) \\
\end{array}$ & $\begin{array}{c}\frac{\Delta \gamma}{2} \\
(\%) \\
\end{array}$ & $\lambda$ & $\begin{array}{c}\frac{\Delta \sigma}{2} \\
(\mathrm{MPa})\end{array}$ & $\begin{array}{c}\frac{\Delta \tau}{2} \\
(\mathrm{MPa})\end{array}$ & $\begin{array}{c}\frac{\Delta \gamma_{\max }}{2} \\
(\%)\end{array}$ & $\begin{array}{l}\Delta \varepsilon_{n} \\
(\%)\end{array}$ & $\begin{array}{l}\sigma_{n, \max } \\
(\mathrm{MPa})\end{array}$ & $N_{f}$ \\
\hline \multicolumn{10}{|c|}{ Base-metal fatigue test } \\
\hline UA & 0.60 & 0 & 0 & 270 & 0 & 0.87 & 0.16 & 135 & 3443 \\
\hline UA & 0.60 & 0 & 0 & 273 & 0 & 0.87 & 0.16 & 137 & 4012 \\
\hline UA & 0.80 & 0 & 0 & 289 & 0 & 1.17 & 0.21 & 145 & 1643 \\
\hline UA & 0.80 & 0 & 0 & 288 & 0 & 1.17 & 0.21 & 144 & 1817 \\
\hline UA & 1.03 & 0 & 0 & 302 & 0 & 1.51 & 0.27 & 151 & 1257 \\
\hline UA & 1.01 & 0 & 0 & 299 & 0 & 1.49 & 0.27 & 149 & 1254 \\
\hline IP & 0.27 & 0.50 & 1.852 & 194 & 88 & 0.63 & 0.08 & 119 & 16269 \\
\hline IP & 0.42 & 0.74 & 1.762 & 196 & 105 & 0.96 & 0.11 & 107 & 4443 \\
\hline IP & 0.42 & 0.74 & 1.762 & 195 & 107 & 0.96 & 0.11 & 102 & 4535 \\
\hline IP & 0.56 & 0.96 & 1.714 & 214 & 108 & 1.26 & 0.15 & 119 & 2929 \\
\hline IP & 0.56 & 0.97 & 1.732 & 213 & 108 & 1.27 & 0.15 & 118 & 2971 \\
\hline IP & 0.71 & 1.25 & 1.761 & 219 & 111 & 1.63 & 0.19 & 123 & 1475 \\
\hline IP & 0.71 & 1.18 & 1.662 & 218 & 110 & 1.58 & 0.19 & 117 & 2053 \\
\hline OP & 0.40 & 0.69 & 1.725 & 305 & 176 & 0.69 & 0.17 & 313 & 1494 \\
\hline OP & 0.40 & 0.70 & 1.750 & 306 & 170 & 0.70 & 0.17 & 312 & 1519 \\
\hline OP & 0.51 & 0.85 & 1.667 & 326 & 182 & 0.81 & 0.22 & 322 & 1002 \\
\hline OP & 0.50 & 0.81 & 1.620 & 321 & 181 & 0.85 & 0.22 & 326 & 992 \\
\hline OP & 0.61 & 1.01 & 1.656 & 336 & 189 & 1.01 & 0.27 & 336 & 703 \\
\hline OP & 0.61 & 0.99 & 1.623 & 329 & 186 & 0.99 & 0.27 & 329 & 642 \\
\hline \multicolumn{10}{|c|}{ Welded-metal fatigue test } \\
\hline UA & 0.61 & 0 & 0 & 295 & 0 & 0.89 & 0.17 & 147 & 289 \\
\hline UA & 0.60 & 0 & 0 & 293 & 0 & 0.87 & 0.16 & 146 & 432 \\
\hline UA & 0.81 & 0 & 0 & 313 & 0 & 1.18 & 0.22 & 156 & 118 \\
\hline UA & 0.80 & 0 & 0 & 315 & 0 & 1.17 & 0.22 & 157 & 177 \\
\hline UA & 1.02 & 0 & 0 & 329 & 0 & 1.50 & 0.27 & 164 & 70 \\
\hline UA & 1.00 & 0 & 0 & 334 & 0 & 1.47 & 0.27 & 167 & 60 \\
\hline IP & 0.28 & 0.49 & 1.750 & 189 & 104 & 0.63 & 0.08 & 102 & 2697 \\
\hline IP & 0.42 & 0.75 & 1.786 & 221 & 121 & 0.96 & 0.12 & 118 & 1262 \\
\hline IP & 0.42 & 0.74 & 1.762 & 220 & 122 & 0.97 & 0.12 & 120 & 701 \\
\hline IP & 0.57 & 1.01 & 1.772 & 230 & 131 & 1.31 & 0.15 & 127 & 384 \\
\hline IP & 0.56 & 1.00 & 1.786 & 241 & 134 & 1.29 & 0.15 & 129 & 393 \\
\hline IP & 0.71 & 1.25 & 1.761 & 253 & 128 & 1.63 & 0.19 & 142 & 160 \\
\hline IP & 0.70 & 1.27 & 1.814 & 243 & 129 & 1.63 & 0.19 & 135 & 145 \\
\hline OP & 0.40 & 0.69 & 1.725 & 345 & 195 & 0.69 & 0.18 & 345 & 359 \\
\hline OP & 0.41 & 0.68 & 1.659 & 335 & 190 & 0.68 & 0.19 & 335 & 388 \\
\hline OP & 0.49 & 0.88 & 1.796 & 350 & 198 & 0.91 & 0.23 & 362 & 220 \\
\hline OP & 0.50 & 0.91 & 1.820 & 362 & 207 & 0.88 & 0.24 & 356 & 172 \\
\hline OP & 0.63 & 1.03 & 1.635 & 405 & 234 & 0.88 & 0.23 & 390 & 98 \\
\hline OP & 0.56 & 1.07 & 1.911 & 410 & 237 & 1.03 & 0.30 & 383 & 76 \\
\hline
\end{tabular}

the Manson-Coffin equation. Thus, the Kandil-Brown-Miller $(\mathrm{KBM})$ model can be given by

$$
\begin{aligned}
\frac{\Delta \gamma_{\max }}{2}+S \Delta \varepsilon_{n}= & {\left[1+\nu_{e}+\left(1-v_{e}\right) S\right] \frac{\sigma_{f}^{\prime}}{E}\left(2 N_{f}\right)^{b} } \\
& +\left[1+\nu_{p}+\left(1-v_{p}\right) S\right] \varepsilon_{f}^{\prime}\left(2 N_{f}\right)^{c},
\end{aligned}
$$

where $\Delta \gamma_{\max }$ and $\Delta \varepsilon_{n}$ are the maximum shear strain range and the normal strain range acting on the critical plane, respectively. $v_{e}$ and $v_{p}$ are the elastic and plastic Poisson's ratios, respectively. Consistency of volume requires the elastic Poisson's ratio to typically equal 0.3 and the plastic Poisson's ratio to be 0.5 . $S$ is an experimental coefficient of the investigated materials. 
TABLE 5: Fatigue properties of base metal and welded metal.

\begin{tabular}{|c|c|c|c|}
\hline Fatigue properties & Uniaxial tests & In-phase tests & $90^{\circ}$ out-of-phase tests \\
\hline \multicolumn{4}{|c|}{ Base-metal specimen } \\
\hline$\sigma_{f}^{\prime}(\mathrm{MPa})$ & 407.59 & 438.40 & 535.09 \\
\hline$\varepsilon_{f}^{\prime}$ & 0.8091 & 0.6196 & 0.5630 \\
\hline$b$ & -0.0424 & -0.0520 & -0.0702 \\
\hline$c$ & -0.5827 & -0.5277 & -0.6723 \\
\hline \multicolumn{4}{|c|}{ Welded-metal specimen } \\
\hline$\sigma_{f}^{\prime}(\mathrm{MPa})$ & 481.14 & 508.27 & 519.35 \\
\hline$\varepsilon_{f}^{\prime}$ & 0.0375 & 0.0654 & 0.0202 \\
\hline$b$ & -0.0755 & -0.0708 & -0.3555 \\
\hline$c$ & -0.3154 & -0.0624 & -0.3181 \\
\hline
\end{tabular}

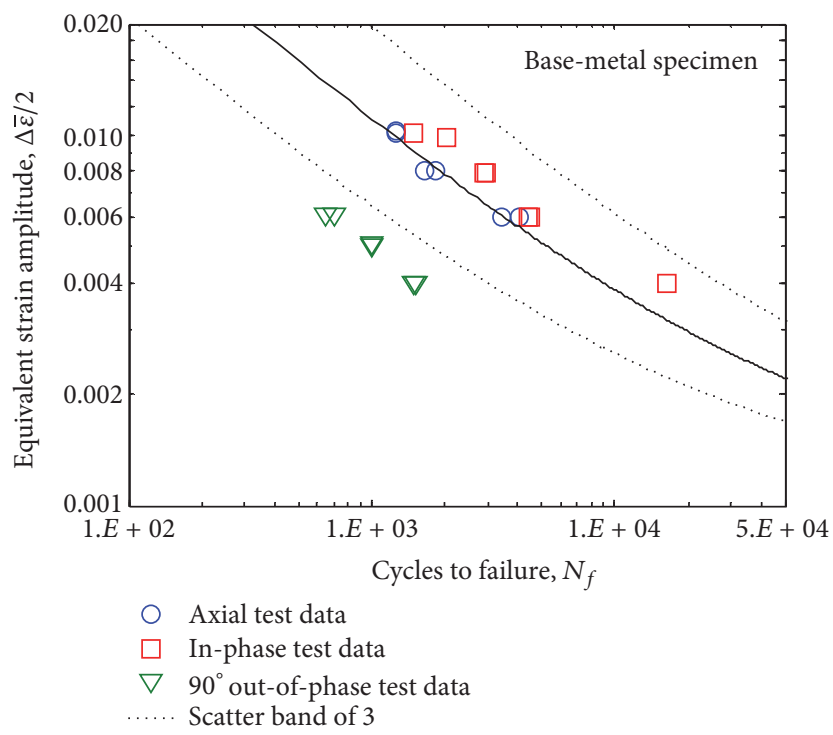

(a)

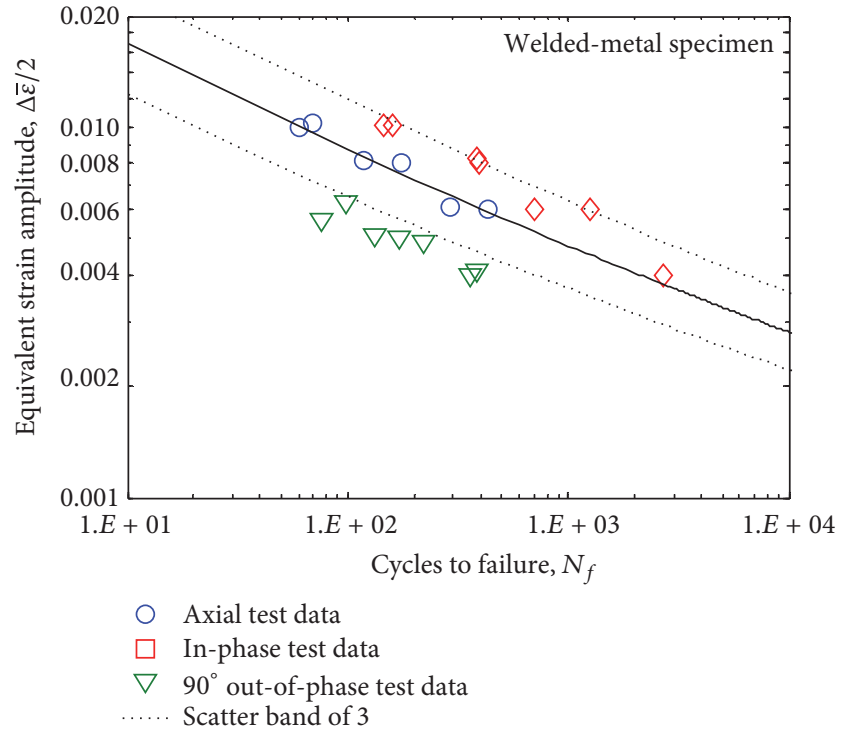

(b)

FIgURE 10: Relationship of equivalent strain versus fatigue life: (a) base metal and (b) welded metal.

Fatemi and Socie [25] proposed a widely accepted critical plane concept using the maximum normal stress, which can reflect the effect of nonproportional cyclic additional hardening on multiaxial fatigue damage to replace the normal strain in KBM parameter. The Fatemi-Socie (FS) model can be written as

$$
\begin{aligned}
& \frac{\Delta \gamma_{\max }}{2}\left(1+k \frac{\sigma_{n, \max }}{\sigma_{y}}\right) \\
& =\left[\left(1+v_{e}\right) \frac{\sigma_{f}^{\prime}}{E}\left(2 N_{f}\right)^{b}+\left(1+v_{p}\right) \varepsilon_{f}^{\prime}\left(2 N_{f}\right)^{c}\right] \\
& \cdot\left(1+k \frac{\sigma_{f}^{\prime}}{2 \sigma_{y}}\left(2 N_{f}\right)^{b}\right),
\end{aligned}
$$

where $\sigma_{n, \max }$ is the maximum normal stress acting on the critical plane. $\sigma_{y}$ is the yield strength for the investigated materials. $k$ is an experimental coefficient. As an approximation, one may simply assume the experimental coefficient in FS model to be 1.0 [10].

Based on the FS critical plane concept, Li and the coauthors [4] developed a stress-correlated factor to consider the effect of the nonproportional additional hardening on multiaxial fatigue damage, which can be used to modify the KBM parameter. The Modified KBM (MKBM) model can be rewritten as

$$
\begin{aligned}
& \frac{\Delta \gamma_{\max }}{2}+\left(1+\frac{\sigma_{n, \max }}{\sigma_{y}}\right) \frac{\Delta \varepsilon_{n}}{2} \\
& =\left[\frac{\sigma_{f}^{\prime}}{E}\left(2 N_{f}\right)^{b}+\varepsilon_{f}^{\prime}\left(2 N_{f}\right)^{c}\right]\left(1+\frac{\sigma_{f}^{\prime}}{\sigma_{y}}\left(2 N_{f}\right)^{b}\right) .
\end{aligned}
$$

Figures 12-14 present the correlation of the KBM, FS, and MKBM parameters with the observed fatigue life. It can be seen that KBM parameters fit well fatigue life data of both base-metal and welded-metal specimens for the uniaxial and 


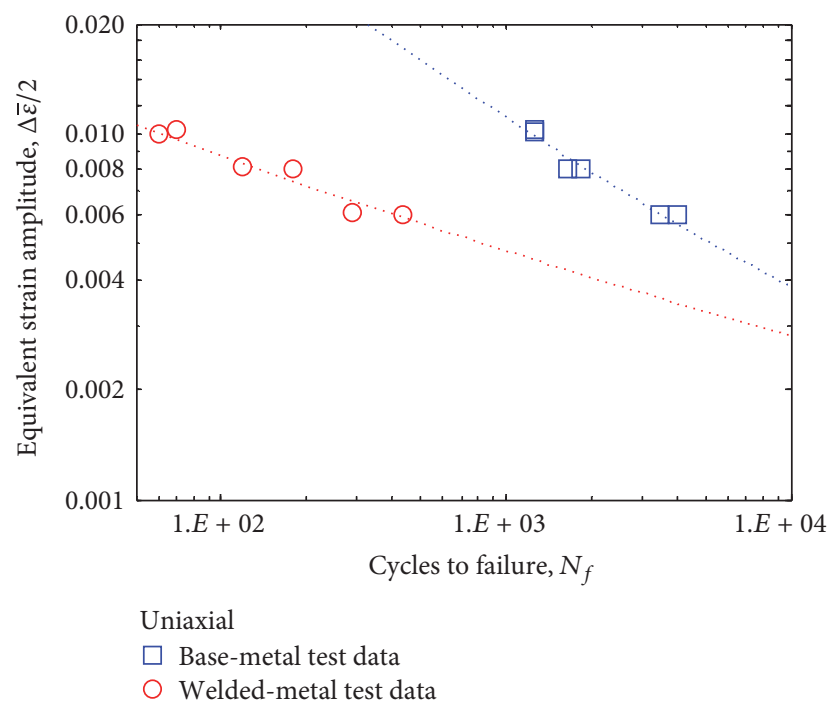

(a)

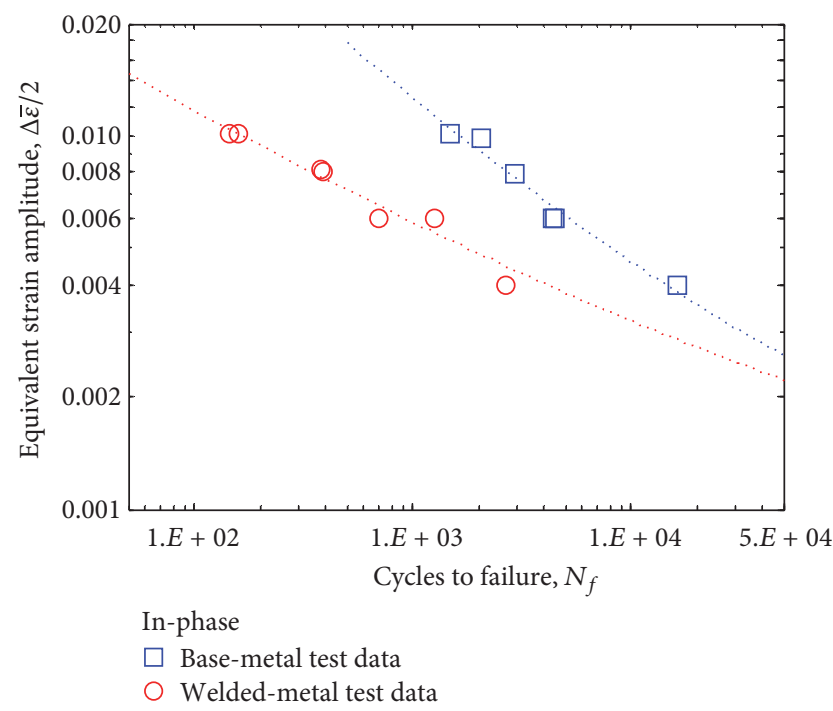

(b)

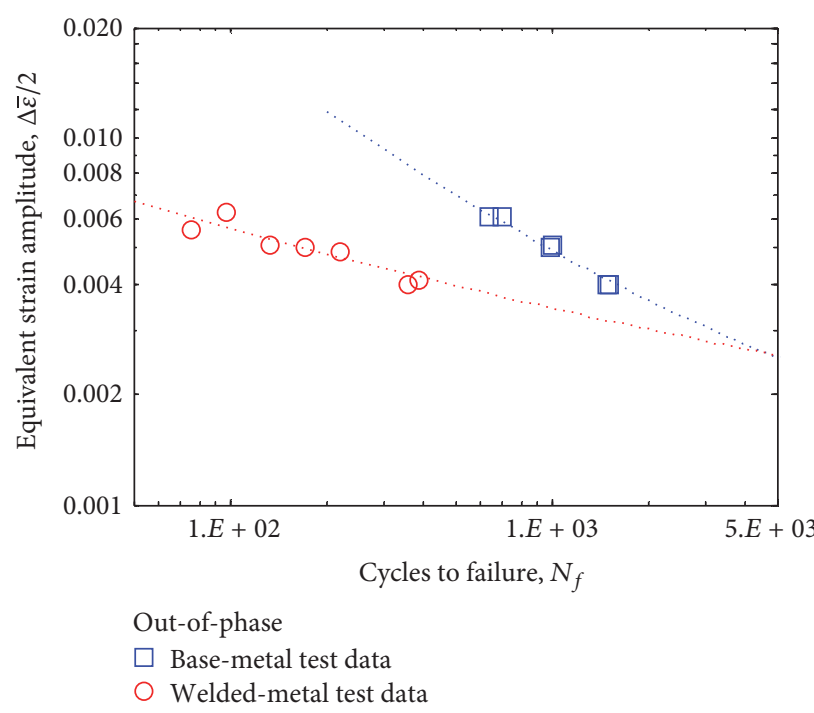

(c)

FIGURE 11: Comparison of fatigue life between base-metal and welded-metal specimen: (a) uniaxial loading, (b) in-phase loading, and (c) $90^{\circ}$ out-of-phase loading.

in-phase tests. No correlation could be found for the $90^{\circ}$ out-of-phase loading condition. It should be noted that the experimental coefficient $S$ in KBM model is taken as 0.8 for the base metal and 1.0 for the welded metal, respectively, which are the averaged values over the fatigue test data.

FS parameters and fatigue life are well correlated for base metal and welded metal for all loading conditions. The correlation of the MKBM parameters with the fatigue life for the out-of-phase loading is greatly improved with respect to KBM, especially for the welded-metal specimens under $90^{\circ}$ out-of-phase loading. The improving predictions of the FS and MKBM parameters for out-of-phase loading conditions can be attributed to the introduced stress term $\sigma_{n \text {,max }}$, which reflects the effect of the material additional cyclic hardening due to the nonproportionality of the cyclic loading on multiaxial fatigue damage.
A critical plane approach should be able to predict both the fatigue life and the critical planes, where cracks are predicted to initiate $[26,27]$. Comparison of theoretical predictions with experimental data allows evaluating the validity of a proposed critical plane approach. However, due to the difficulties in defining cracking direction observed experimentally due to the roughness of the crack surface, limited work has been done in the evaluation of a critical plane approach for predicting the cracking directions. Jiang [26] investigated the cracking behavior predictions of FS model by using 35 thin-walled tubular specimens of S460N steel and found that only about $20 \%$ specimens are predicted correctly by the FS model for the cracking orientations, which reveals that the predictions for the cracking directions are far less desirable than the fatigue life predictions. The time-consuming cracking behavior observation may have 


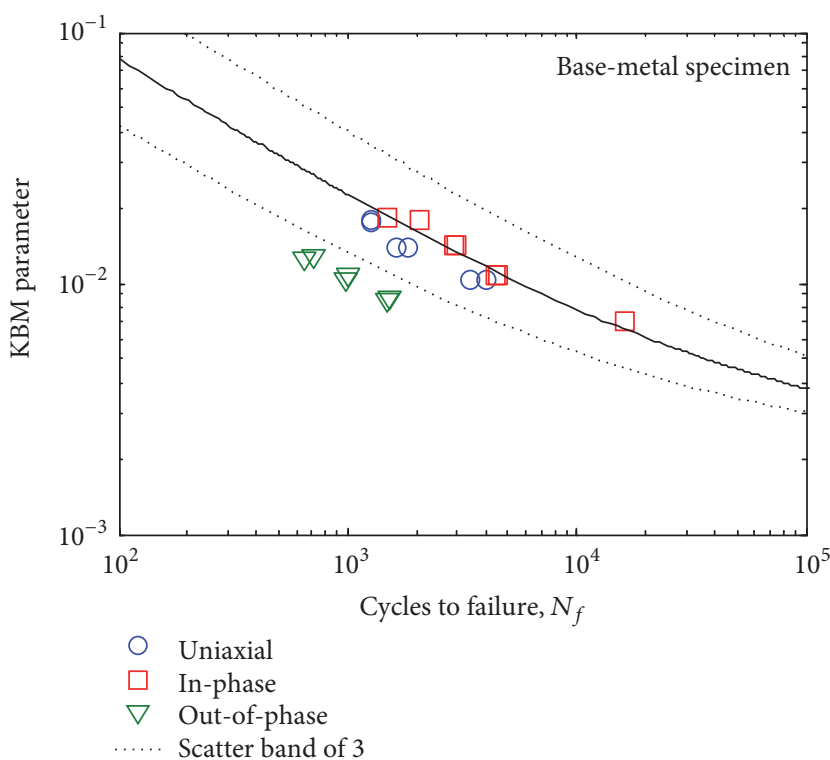

(a)

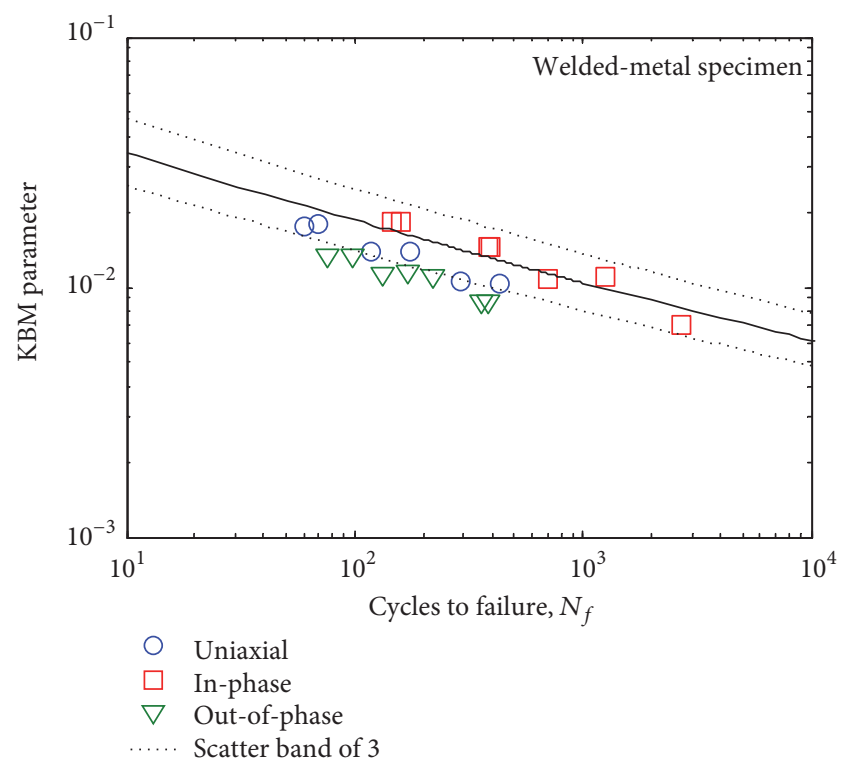

(b)

FIGURE 12: Correlation of KBM parameters with the fatigue life: (a) base metal and (b) welded metal.

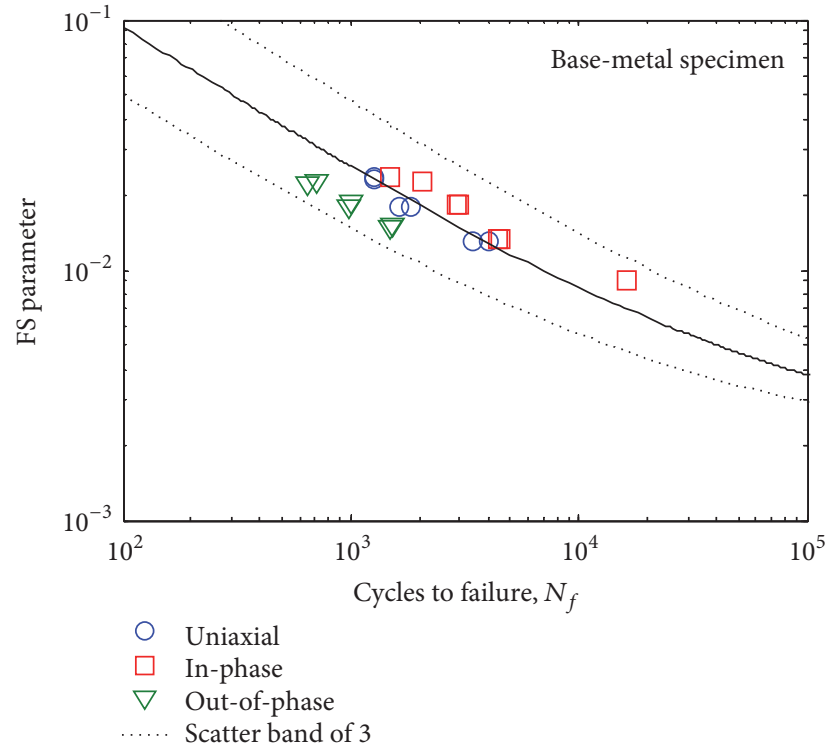

(a)

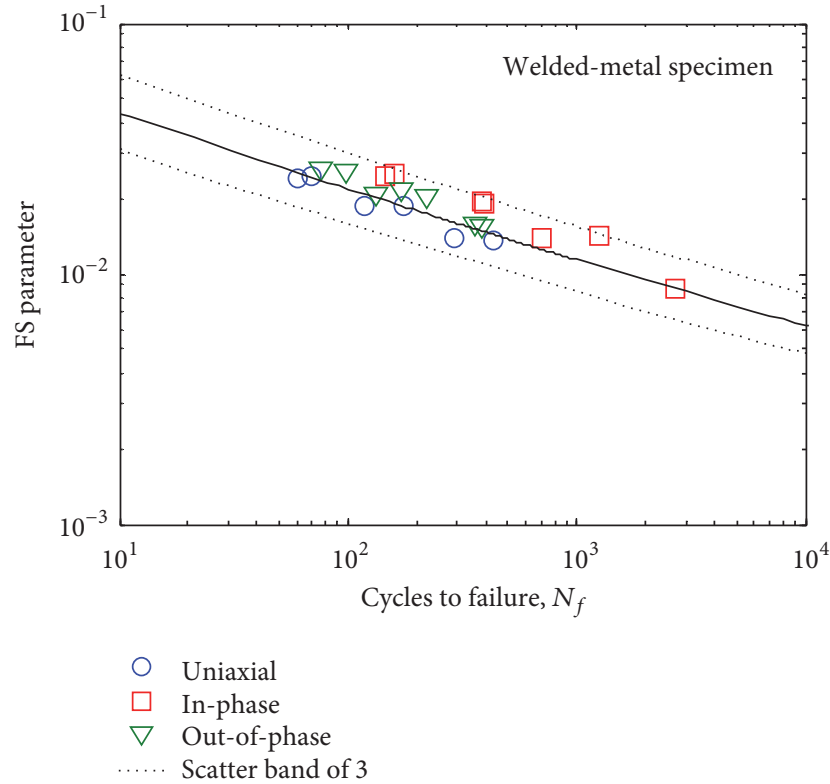

(b)

FIGURE 13: Correlation of FS parameters with the fatigue life: (a) base metal and (b) welded metal.

prevented more detailed work on the cracking direction examinations [26]. Accordingly, it is worth pointing out that the predictions for cracking directions using different critical plane models certainly warrant investigations in the future.

\section{Conclusions}

The multiaxial cycle deformation and fatigue behavior of Q235B mild carbon steel and its related welded metal are experimentally investigated in the present paper. The following conclusions can be drawn:

(1) Significant additional cyclic hardening effect is observed for both base steel and welded metal under out-of-phase loading conditions. Besides, welding proc-ess produces extra additional hardening compared with the base metal.

(2) Fatigue strength under in-phase loading is slightly higher than that under uniaxial loading for both base 


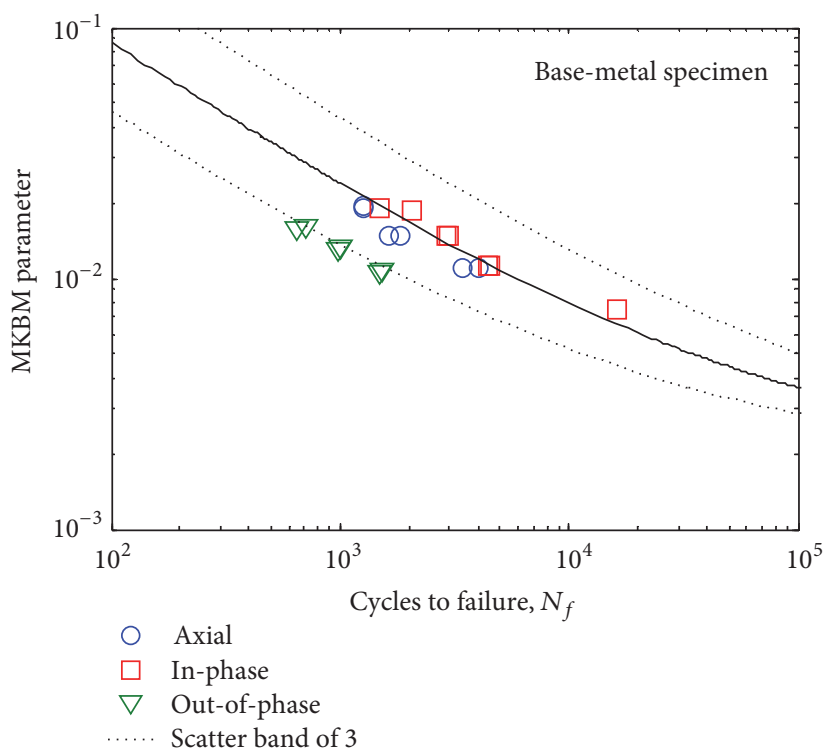

(a)

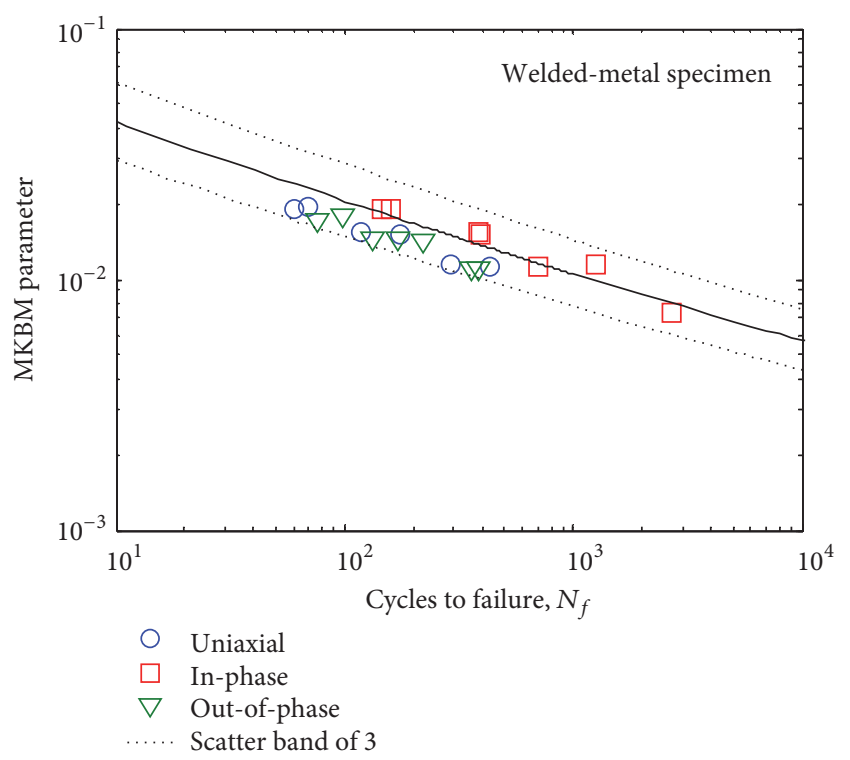

(b)

FIGURE 14: Correlation of MKBM parameters with the fatigue life: (a) base metal and (b) welded metal.

metal and welded metal, while the fatigue strength under $90^{\circ}$ out-of-phase loading is significantly reduced.

(3) Fatigue strength for welded-metal specimens is greatly reduced compared with the base metal under the same loading conditions, and the fatigue life reduction of the weldment increases with increasing applied strain amplitudes.

(4) The FS and the MKBM parameters show better correlation with fatigue life for both base-metal and welded-metal specimens. The good correlation can be attributed to the introduction of maximum normal stress acting on the critical plane, which can reflect the influence of the nonproportional hardening on multiaxial fatigue damage.

\section{Competing Interests}

The authors declare that there are no competing interests regarding the publication of this paper.

\section{Acknowledgments}

The authors would like to thank Professor Keshi Zhang in Guangxi University for providing the fatigue test equipment and invaluable comments on the experimental study. The authors also gratefully acknowledge the financial support for this work from National Natural Science Foundation of China (nos. 51378409 and 51438002).

\section{References}

[1] A. Karolczuk and E. Macha, "A review of critical plane orientations in multiaxial fatigue failure criteria of metallic materials,"
International Journal of Fracture, vol. 134, no. 3-4, pp. 267-304, 2005.

[2] J. Das and S. M. Sivakumar, "An evaluation of multiaxial fatigue life assessment methods for engineering components," International Journal of Pressure Vessels and Piping, vol. 76, no. 10, pp. 741-746, 1999.

[3] C. M. Sonsino, "Effect of residual stresses on the fatigue behaviour of welded joints depending on loading conditions and weld geometry," International Journal of Fatigue, vol. 31, no. 1, pp. 88101, 2009.

[4] J. Li, Z.-P. Zhang, Q. Sun, and C.-W. Li, "Multiaxial fatigue life prediction for various metallic materials based on the critical plane approach," International Journal of Fatigue, vol. 33, no. 2, pp. 90-101, 2011.

[5] B. C. Li, C. Jiang, X. Han, and Y. Li, "A new path-dependent multiaxial fatigue model for metals under different paths," Fatigue \& Fracture of Engineering Materials \& Structures, vol. 37, no. 2, pp. 206-218, 2014.

[6] X. Chen, D. Jin, and K. S. Kim, "Fatigue life prediction of type 304 stainless steel under sequential biaxial loading," International Journal of Fatigue, vol. 28, no. 3, pp. 289-299, 2006.

[7] Z. Gao, T. Zhao, X. Wang, and Y. Jiang, "Multiaxial fatigue of 16MnR steel," Journal of Pressure Vessel Technology, vol. 131, no. 2, pp. 73-80, 2009.

[8] T. Zhao and Y. Jiang, "Fatigue of 7075-T651 aluminum alloy," International Journal of Fatigue, vol. 30, no. 5, pp. 834-849, 2008.

[9] D. G. Shang and D. J. Wang, Multiaxial Fatigue Strength, Science Press, Beijing, China, 2007 (Chinese).

[10] N. Shamsaei, Multiaxial Fatigue and Deformation Including Non-Proportional Hardening and Variable Amplitude Loading Effects, The University of Toledo Dissertations, 2010.

[11] M. Gladskyi and S. Shukaev, "A new model for low cycle fatigue of metal alloys under non-proportional loading," International Journal of Fatigue, vol. 32, no. 10, pp. 1568-1572, 2010. 
[12] D. Radaj, C. M. Sonsino, and W. Fricke, Fatigue Assessment of Welded Joints by Local Approaches, Wood Publishing Limited, Cambridge, UK, 2006.

[13] V. Caccese, P. A. Blomquist, K. A. Berube, S. R. Webber, and N. J. Orozco, "Effect of weld geometric profile on fatigue life of cruciform welds made by laser/GMAW processes," Marine Structures, vol. 19, no. 1, pp. 1-22, 2006.

[14] S. J. Kim, R. T. Dewa, W. G. Kim, and M. H. Kim, "Cyclic stress response and fracture behaviors of Alloy 617 base metal and weld joints under LCF loading," Advances in Materials Science and Engineering, vol. 2015, Article ID 207497, 11 pages, 2015.

[15] A. Hobbacher, Recommendations for Fatigue Design of Welded Joints and Components, International Institute of Welding, XIII1539-96/XV-845-96, 2007.

[16] Eurocode 3, Design of Steel Structures. Part 1-9: Fatigue, European Standard EN 1993-1-9, 2005.

[17] BS5400, Steel, Concrete and Composite Bridges. Part 10: Code of Practice for Fatigue, BS5400, 1980.

[18] X. Chen, K. An, and K. S. Kim, "Low-cycle fatigue of $1 \mathrm{Cr}-18 \mathrm{Ni}-$ 9Ti stainless steel and related weld metal under axial, torsional and $90^{\circ}$ out-of-phase loading," Fatigue \& Fracture of Engineering Materials \& Structures, vol. 27, no. 6, pp. 439-448, 2004.

[19] M. Bäckström and G. Marquis, "A review of multiaxial fatigue of weldments: experimental results, design code and critical plane approaches," Fatigue \& Fracture of Engineering Materials \& Structures, vol. 24, no. 5, pp. 279-291, 2001.

[20] J. Szusta and A. Seweryn, "Low-cycle fatigue model of damage accumulation-the strain approach," Engineering Fracture Mechanics, vol. 77, no. 10, pp. 1604-1616, 2010.

[21] A. Karolczuk and E. Macha, "A review of critical plane orientations in multiaxial fatigue failure criteria of metallic materials," International Journal of Fracture, vol. 134, no. 3-4, pp. 267-304, 2005.

[22] D. F. Socie and G. B. Marquis, Multiaxial Fatigue, Society of Automotive Engineers, Warrendale, Pa, USA, 2000.

[23] N. Shamsaei and A. Fatemi, "Effect of microstructure and hardness on non-proportional cyclic hardening coefficient and predictions," Materials Science and Engineering A, vol. 527, no. 12, pp. 3015-3024, 2010.

[24] Y. Wang, X. Liu, G. Dai, and Y. Shi, "Experimental study on constitutive relation of steel SN490B under cyclic loading," Journal of Building Structures, vol. 35, no. 4, pp. 142-148, 2014.

[25] A. Fatemi and D. F. Socie, "A critical plane approach to multiaxial fatigue damage including out-of-phase loading," Fatigue \& Fracture of Engineering Materials \& Structures, vol. 11, no. 3, pp. 149-165, 1988.

[26] Y. Jiang, "Fatigue criterion for general multiaxial loading," Fatigue and Fracture of Engineering Materials and Structures, vol. 23, no. 1, pp. 19-32, 2000.

[27] D. McClaflin and A. Fatemi, "Torsional deformation and fatigue of hardened steel including mean stress and stress gradient effects," International Journal of Fatigue, vol. 26, no. 7, pp. 773784, 2004. 

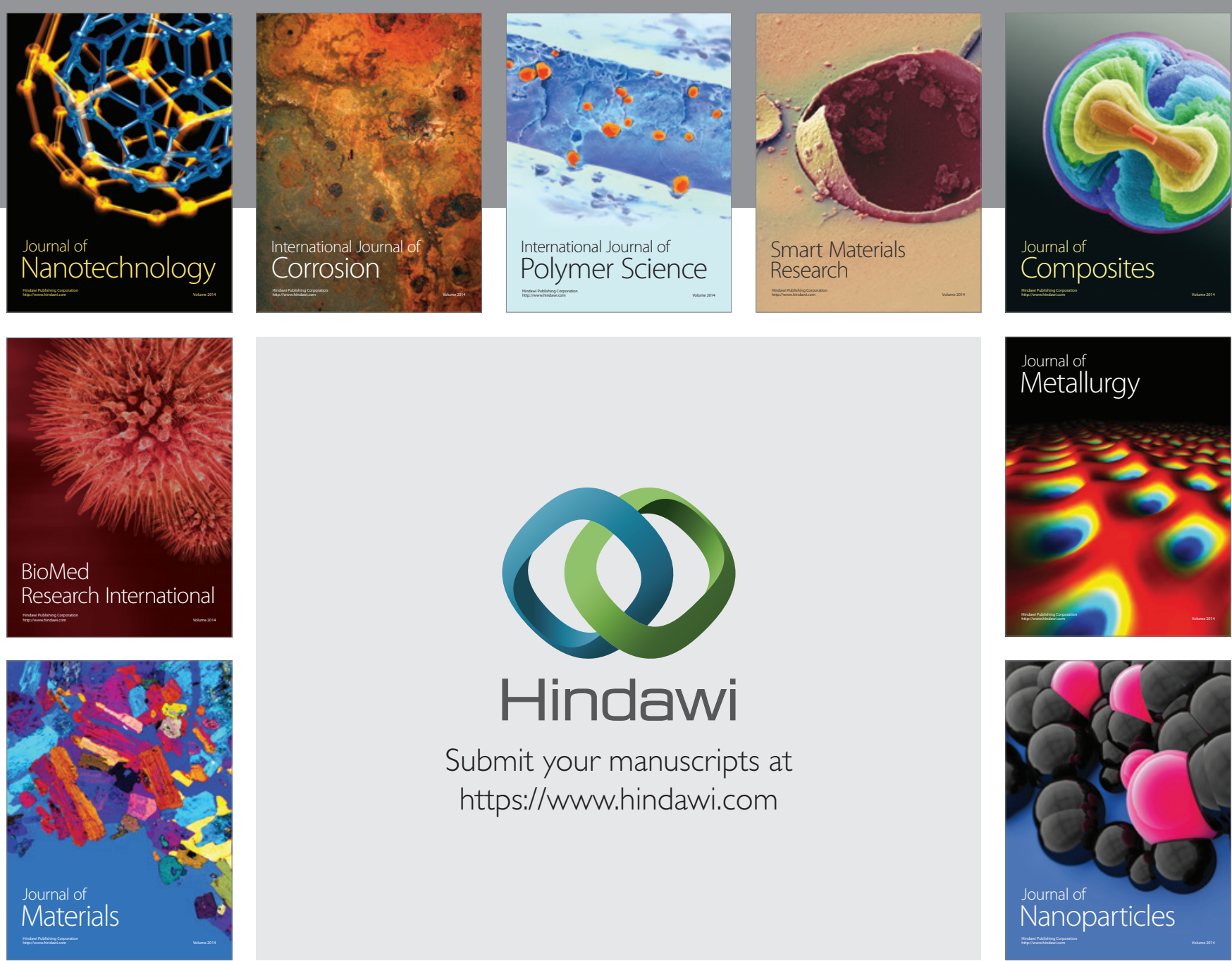

\section{Hindawi}

Submit your manuscripts at

https://www.hindawi.com

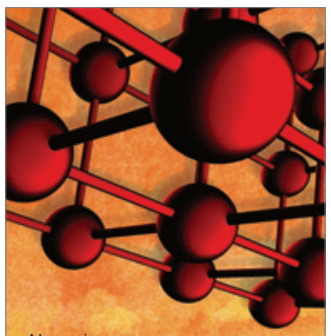

Materials Science and Engineering
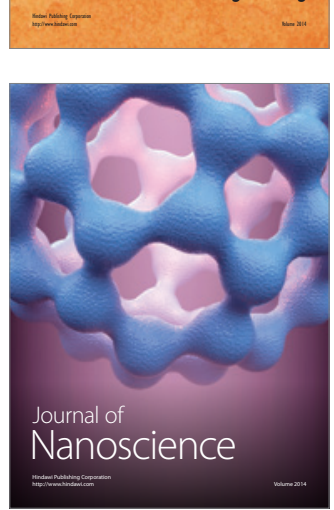
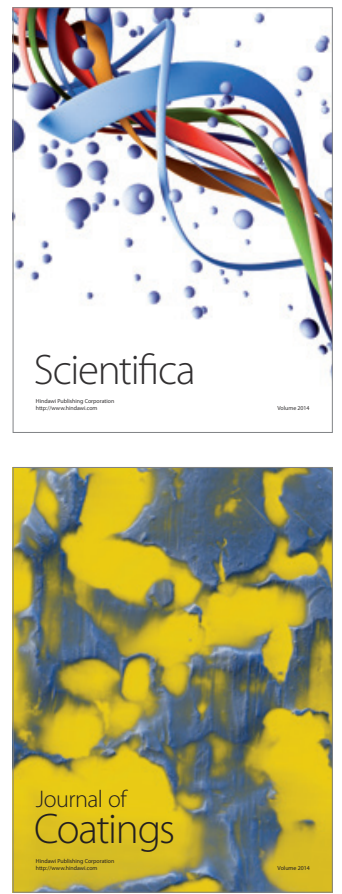
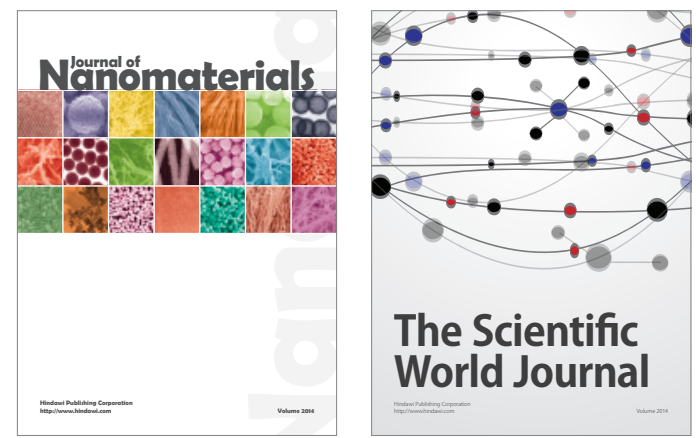

The Scientific World Journal
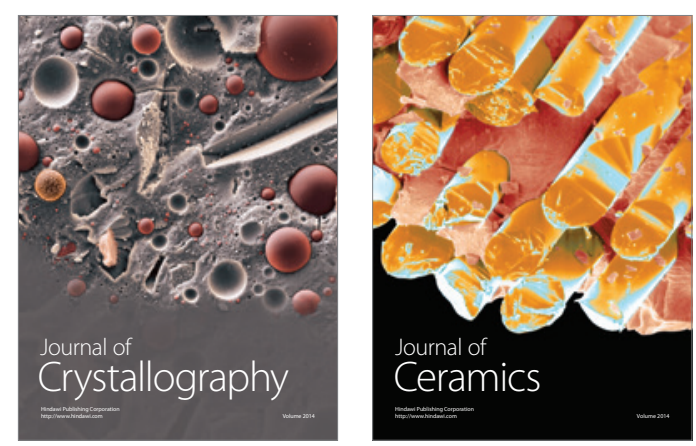
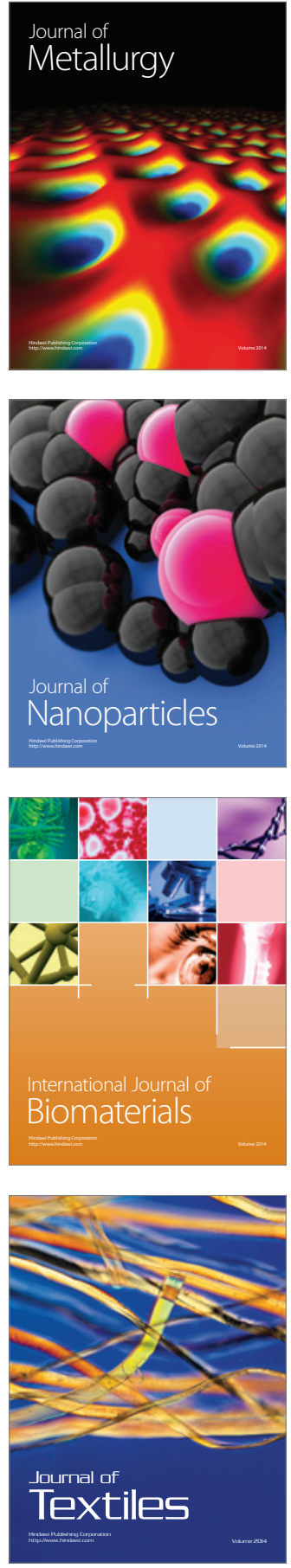